Western University

Scholarship@Western

Surgery Publications

Surgery Department

$6-2010$

Management of Devastating Ocular Trauma-Experience of Maxillofacial Surgeons Deployed to a Forward Field Hospital

M. J. Ansell

Queen Alexandra Hospital, Portsmouth, UK

J. Breeze

Centre for Defence Medicine, Birmingham, UK

Vivian C. McAlister

The University of Western Ontario,vmcalist@uwo.ca

M.D. Williams

Eastbourne District General Hospital, East Sussex, UK

Follow this and additional works at: https://ir.lib.uwo.ca/surgerypub

Part of the Ophthalmology Commons, and the Surgery Commons

Citation of this paper:

Ansell, M. J.; Breeze, J.; McAlister, Vivian C.; and Williams, M. D., "Management of Devastating Ocular Trauma--Experience of Maxillofacial Surgeons Deployed to a Forward Field Hospital" (2010). Surgery Publications. 53.

https://ir.lib.uwo.ca/surgerypub/53 


\section{Management of Devastating Ocular Trauma - experience of Maxillofacial Surgeons deployed to a Forward Field Hospital}

Ansell $\mathrm{M} \mathrm{J}{ }^{1}$, Breeze $\mathrm{J}^{2}$, McAlister VC ${ }^{3}$ Williams M D ${ }^{4}$

${ }^{1}$ Trainee in Maxillofacial Surgery, Queen Alexandra Hospital, Portsmouth

${ }^{2}$ Trainee in Maxillofacial Surgery, Centre for Defence Medicine, Birmingham

${ }^{3}$ General Surgeon, Canadian Forces Medical Service

${ }^{4}$ Consultant Maxillofacial Surgeon, Eastbourne District General Hospital, Kings Drive,

Eastbourne, East Sussex, Deployed Consultant Role 3 Hospital Kandahar

\section{Keywords}

Ocular

Trauma

Military

Evisceration

Enucleation

\section{Corresponding Author}

Major Mark Ansell RAMC

mark.ansell@porthosp.nhs.uk 


\section{Abstract}

Combat related eye injuries continue to increase in frequency and are generally secondary to Improvised Explosive Devices. Many ocular injuries are potentially preventable by the wearing of ballistic eye protection. The management of penetrating eye trauma is normally outside the routine practice of maxillofacial surgeons in the UK. The aim of this paper is to describe the surgical techniques used in the modern management of devastating ocular trauma including selected case examples managed by British military maxillofacial surgeons deployed to Afghanistan. 


\section{Introduction}

The incidence of military head, face and neck injuries has increased in modern conflict in comparison to that seen in the last century. Owens et al [1] reported that $29 \%$ of all battle wounds during Operation Iraqi Freedom (OIF) and Operation Enduring Freedom (OEF) involved the head and neck compared with $16 \%$ during the Vietnamese War. Additionally, Wade et al [2] reported that $39 \%$ of battle-injured patients in the Navy-Marine Corps Combat Trauma Registry from OIF sustained trauma to the head, face, and neck.

An increasing trend in the incidence of ocular combat injuries has also been well documented. The reported incidence in the 19 th century was $1 \%$ [3], which rose to between $2 \%$ and $2.5 \%$ during World Wars I and II [3]. Incidences of ocular injury in the $21^{\text {st }}$ century by US forces reveal an incidence between $6 \%[1,2]$ and $10 \%$ [4]. Mader et al [4] found that blast fragmentation from munitions caused $82 \%$ of all injuries in US servicemen deployed on OIF, the most common single cause of which was the improvised explosive device (IED) (51\% of all injuries).

The ocular surface area represents only $0.27 \%$ of the body surface area. However the eye casualty rate in combat is 20 to 50 times greater than expected based on the body surface area [3]. Thoraco- abdominal protection provided by modern body armour has played its part in increasing the survivability of many previously fatal injuries, shifting the area of wounding to the exposed extremities, including the face and eyes. IED's produce multiple high-velocity projectiles that cover a large body surface area but are potentially stopped by simple eye protection. The benefit of eye protection is demonstrated in Figures 1 and 2, showing two coalition servicemen injured on a foot patrol by an IED. Figure 1 was wearing ballistic eye protection and received no significant injury to his eyes. Figure 2, who had momentarily removed his eye protection, received shrapnel spray to his face with complete 
rupture of his left eye and scleral perforation of his right eye. To date no author has definitively published data comparing the incidence of eye injuries in different coalition forces wearing different types of eye protection or between those wearing no ocular protection.

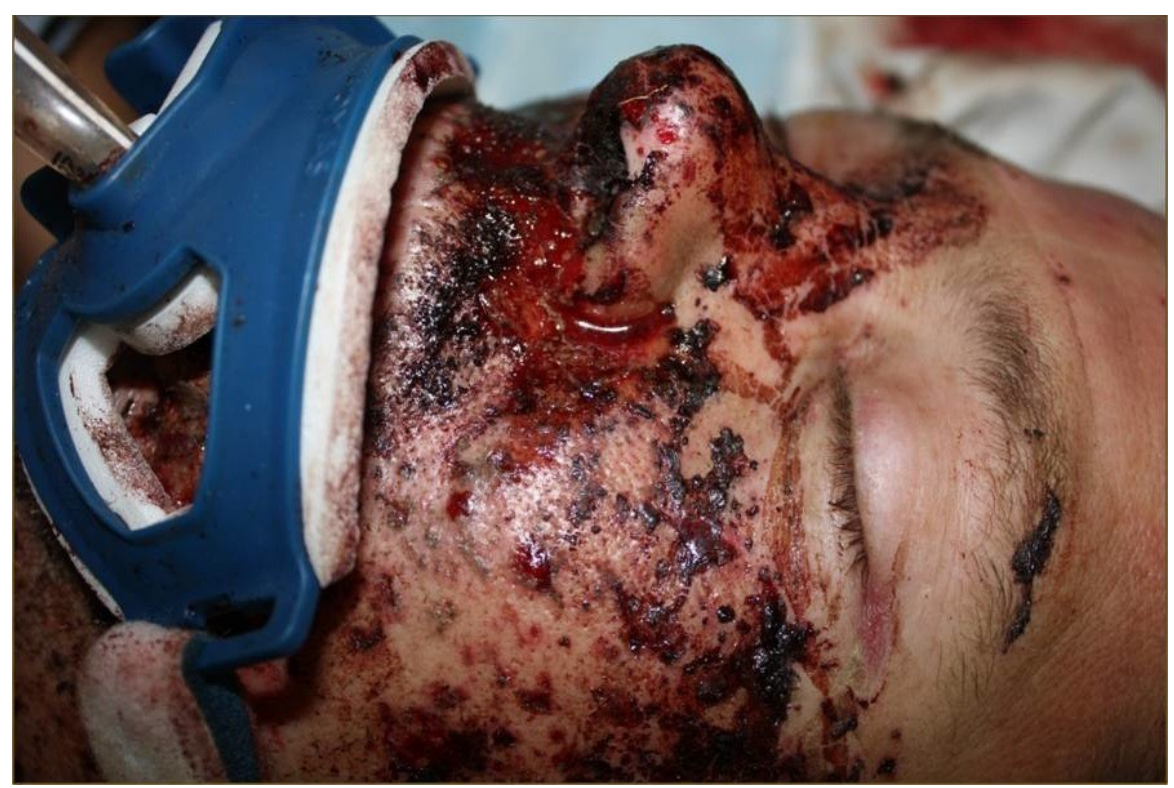

Figure 1: Coalition serviceman hit by an IED on foot patrol wearing issued eye protection

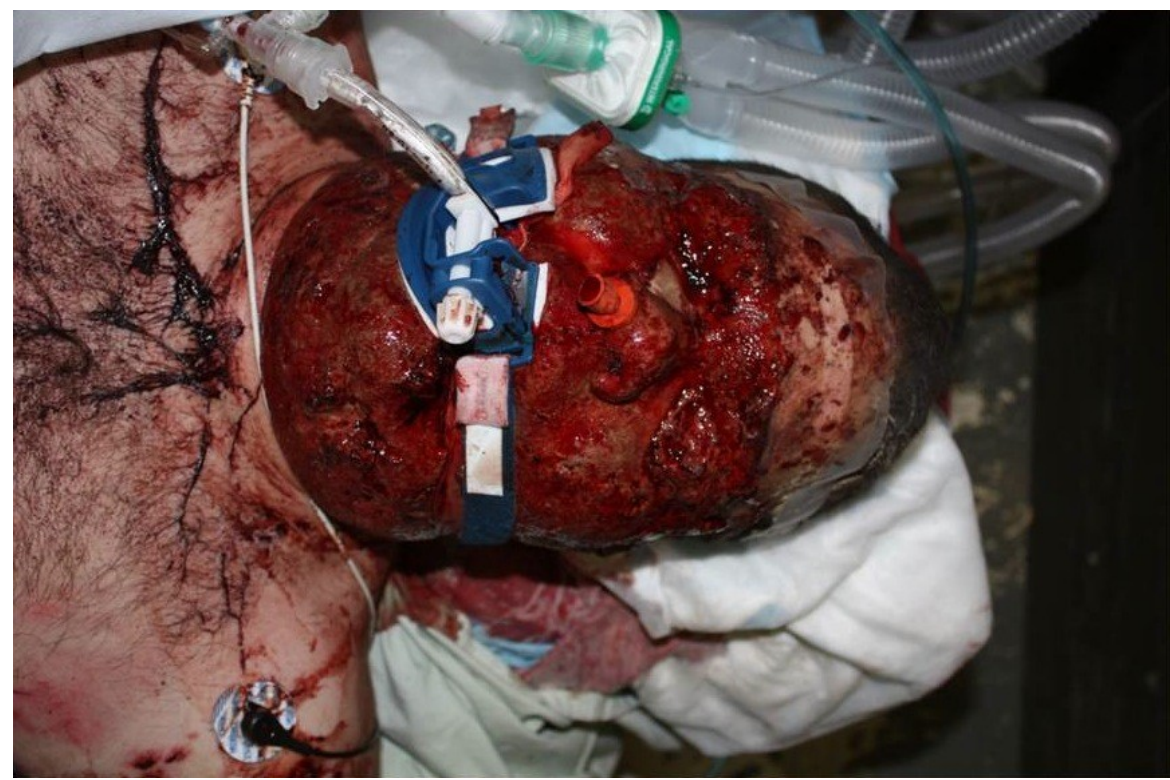

Figure 2: Coalition servicemen in same patrol not wearing eye protection

The British Maxillofacial Cadre has deployed to the multinational hospital in Kandahar for two separate blocks of one year each, with consecutive consultant surgeons deploying for 
two months at a time. The second block was for a 21- month period, between 01 Feb 2007 and 31 Oct 2008, on which this paper is based. Casualties treated included coalition servicemen, local police, army and civilians as well as hostile forces. Great emphasis is placed on the multidisciplinary nature of the team, with surgeons representing the specialities of general surgery, orthopaedic/trauma surgery and maxillofacial surgery. Neurosurgeons were present for less than half of the 2 year deployment. At no time were ophthalmic surgeons present and it fell to the maxillofacial surgeons to manage these casualties. The management of penetrating eye injuries is normally outside the routine practice of Maxillofacial Surgeons in the UK and therefore the aim of this paper is to provide an overview of the types of ocular injuries seen and case examples of the surgical techniques utilised in their management. 


\section{Management of ocular trauma in coalition servicemen}

Coalition forces are managed on an immediate life, limb or sight saving surgery basis and then rapidly evacuated for definitive medical care in the UK for British servicemen or Germany for US and Canadian servicemen. Treatment was generally limited to debridement of ocular injuries and protection by a Morgan eye shield with the administration of tetanus toxoid, prophylactic systemic and topical antibiotics prior to evacuation. 


\section{Management of ocular trauma in the indigenous population}

For this population group definitive surgery was undertaken in Kandahar to minimise the risks of infection and sympathetic ophthalmia due to the limited healthcare facilities available in Afghanistan. Consideration was also given to adequate cosmesis as well as making the remaining eye safe. If the eye was deemed salvageable then the patient was referred to the Non Governmental Organisation (NGO) Eye Surgeon in Kabul.

The vast majority of open globes can be repaired without requiring primary enucleation [5]. However if the eye was deemed non-salvageable the following three options were possible and are illustrated in figure 3.

- Enucleation with immediate prosthesis

- Enucleation with delayed insertion of prosthesis

- Evisceration

Enucleation involves removing both the globe and a segment of the anterior optic nerve, while preserving all other orbital structures, taking care to preserve the conjunctiva [6].

Evisceration is the removal of the contents of the globe while leaving the sclera and extraocular muscles intact. The evisceration process removes the ocular contents but preserves the sclera and, in some cases, the cornea. Ideally surgeons should attempt to avoid enucleation as a primary procedure unless the patient has been properly counselled and consented [7]. It is better to perform a primary repair allowing the eye to be eviscerated or enucleated later; however in mass- casualty situations this may be difficult to achieve.

The goals of evisceration and enucleation are the same (figure 4). Although no firm consensus exists on the indications for evisceration, most experts agree that a patient with a blind, painful eye without risk of intraocular malignancy is a good candidate for the 
technique [6]. Additionally, eyes lost to endophthalmitis may be best treated with evisceration. The advantages and disadvantages of enucleation with immediate prosthesis, enucleation with delayed insertion of prosthesis and evisceration are displayed in figures 5 - 7 .

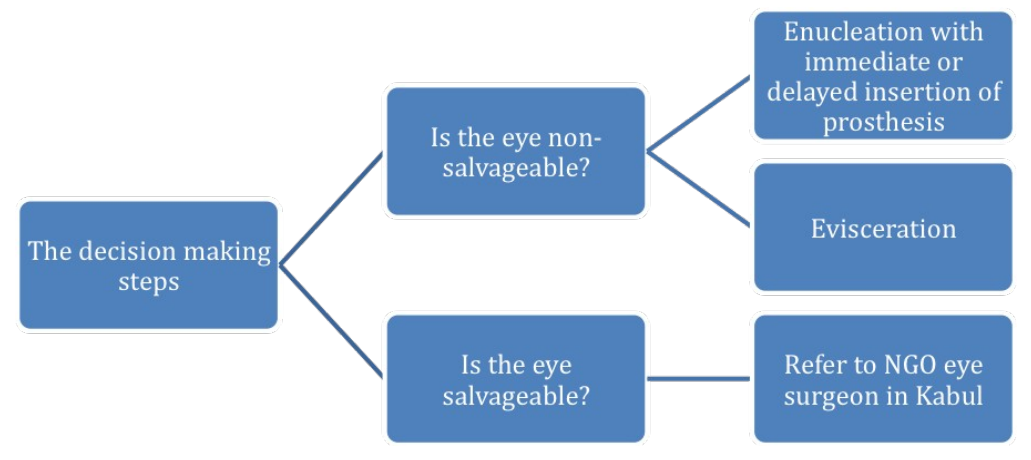

Figure 3: Treatment options for management of ocular trauma in the indigenous population

Figure 4: Surgical goals of enucleation and evisceration

- To achieve a centrally placed inert implant with adequate anterior coverage

- To achieve appropriate volume replacement in the orbit

- To maintain deep fornices and eyelid support for the placement of a prosthesis

- To provide symmetry with the contralateral orbit

- To allow for maximum socket motility, with translation of forces to the prosthesis 
Figure 5: Advantages and disadvantages of enucleation and immediate repair with prosthesis

Advantages

- Single stage procedure

Disadvantages

- Risk of infection from contaminated orbital content

- Difficulty closing extra ocular muscles over implant

Figure 6: Advantages and disadvantages of delayed staged repair

Advantages

- Ensures orbital content is safe

- Fibrotic reaction in muscles leads to more robust closure over the implant

Disadvantages

- A two stage procedure with possibility of casualty not returning to unit

- Protracted timeline requiring extended theatre and ward bed times

Figure 7: Advantages and

disadvantages of evisceration

Advantages

- To reduce risk of implant extrusion

- To reduce risk of infection

- Better cosmesis with a mobile globe

\section{Disadvantages}

- Technically difficult 


\section{Case example 1 (coalition serviceman)}

This coalition serviceman whose injuries can be seen in Figure 2 had momentarily removed his eye protection before being injured by a roadside IED. He received shrapnel spray to his face with complete rupture of his left eye and a scleral perforation of his right eye. Management was to repair the right eye scleral penetration with prolene sutures and rapid evacuation for definitive treatment with a US ophthalmic surgeon. Although the left eye was obviously not salvageable, the decision was made not to enucleate or eviscerate it at the time of surgery to the right eye as it was felt that such casualties should be given time to accept the diagnosis allowing appropriate consent.

\section{Case study 2 (indigenous population)}

A young boy injured by shrapnel with a rupture of globe whose injuries can be seen in figure 8. The shrapnel fragment was removed and scleral sac being salvageable was repaired by primary closure. The scleral contents were enucleated with curettage and the scleral sack was washed out with hydrogen peroxide. Medpor coral implants were inserted, having been previously soaked in bacitracin and the scleral sac closed primarily over the defect (figure 9).

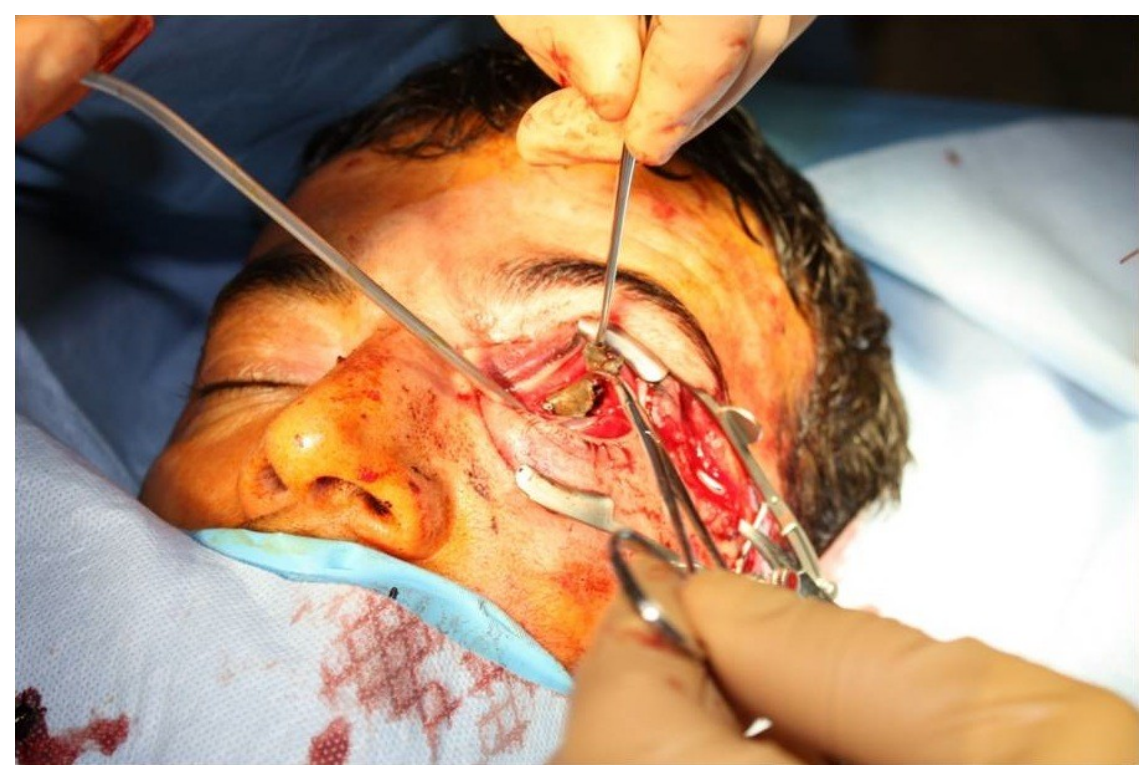


Figure 8: Presentation of intraoccular shrapnel injury

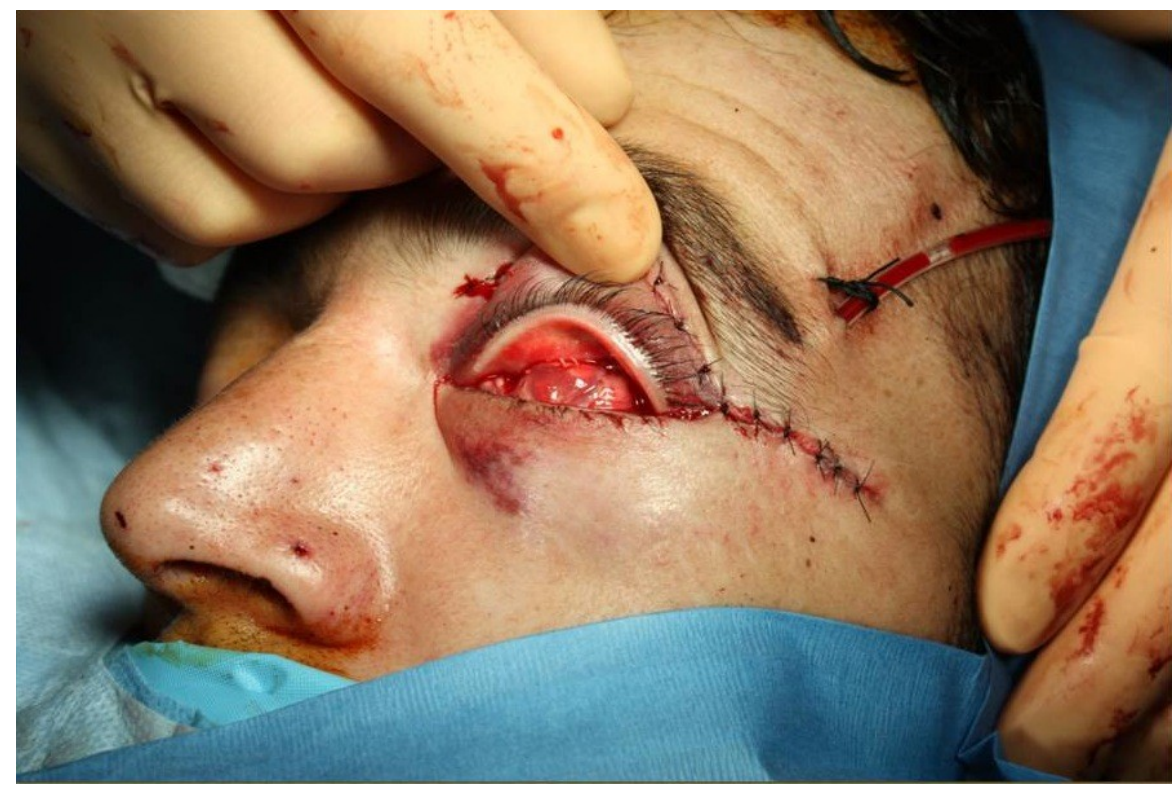

Figure 9: Post insertion of medpor coral implants

\section{Case study 3 (indigenous population)}

This case demonstrates an Afghan Army soldier hit by shrapnel from an IED resulting in extensive globe injuries that were obviously impossible to salvage. The eye was enucleated, leaving the extra ocular muscles with optic nerve divided and tied off (Figure 10). The intra-conal space was washed with Betadine, hydrogen peroxide and saline and packed with iodoform ribbon gauze. Finally the eye lids were repaired and the fornices preserved with a Morgan eye shield.

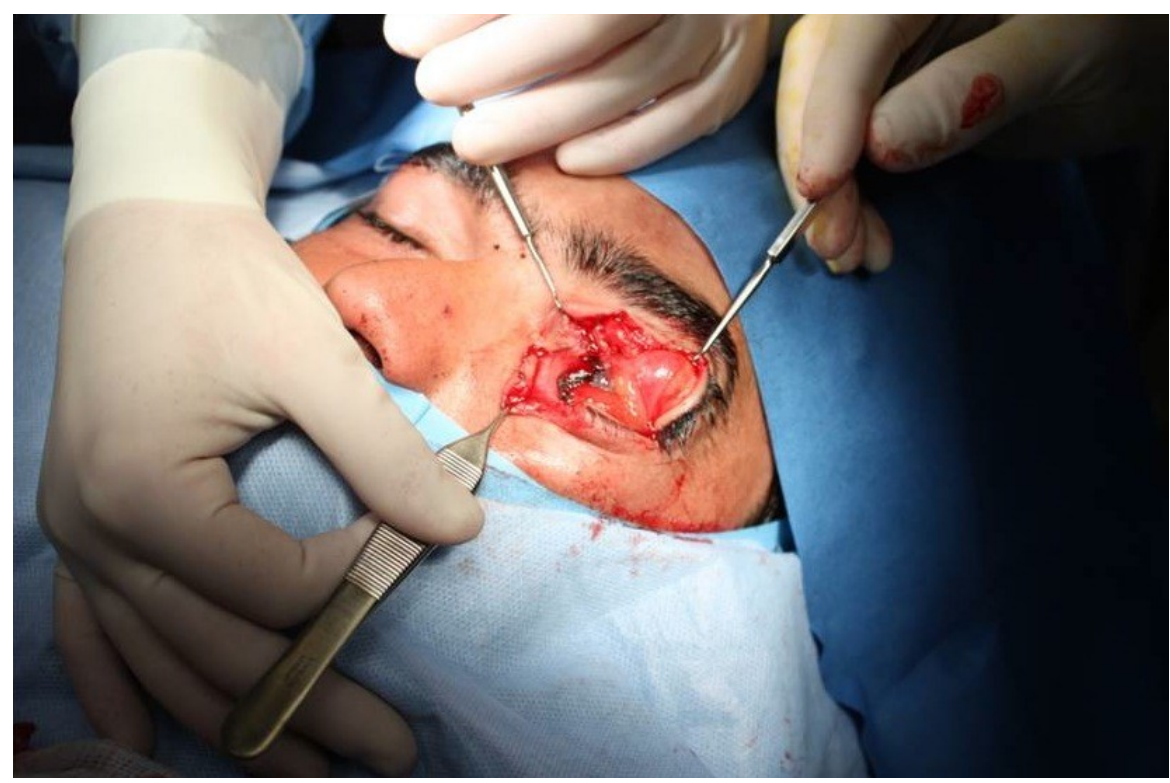


Figure 10: Presentation post enucleation

The patient returned to theatre one week later where the pack was removed. Coral implants were inserted with the extra ocular muscles closed over the implant and the conjunctiva closed over muscles (figure 11).

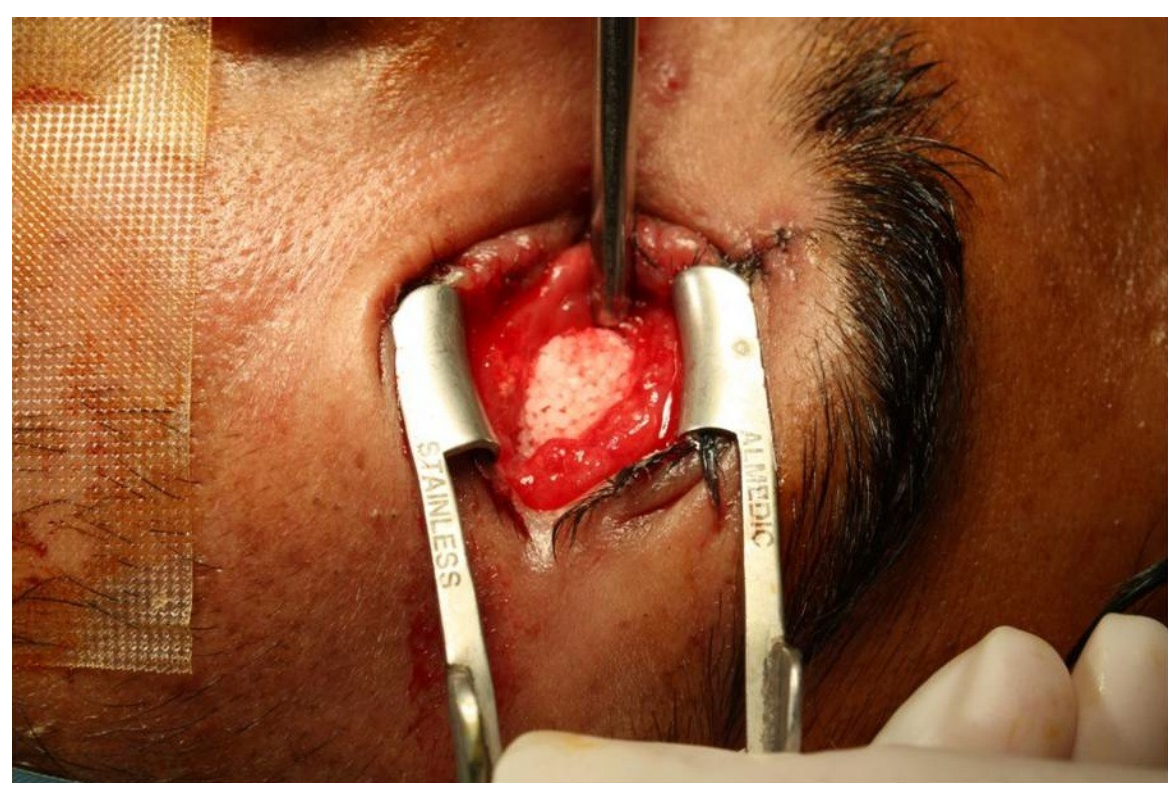

Figure 11: Implants in situ 


\section{Discussion}

Perforated globe injuries sustained in combat generally result in poor visual and anatomical outcomes despite surgical intervention [8]. There is little evidence to favour the techniques of enucleation and evisceration over one another. Enucleations are generally carried out more commonly than eviscerations in both military and civilian practice. However a recent survey of 297 UK consultant ophthalmologists [9] found two- thirds preferred evisceration over enucleation but reasons for this were not given. On the question of choice of implant, $12 \%$ preferred natural coral implants, coincident with the material available and used in theatre by deployed British maxillofacial surgeons. Savar et al [5] looked at 660 open globe injuries over a 5- year period admitted to a civilian trauma centre in the US; 51 underwent enucleation and only 4 had eviscerations. These proportions were similar to those found in the 21- month period that Oral and Maxillofacial surgeons deployed to Kandahar in which 19 eye enucleations and 3 eviscerations were performed.

The most serious complication of both enucleation and evisceration is the risk of developing sympathetic ophthalmia. This is a rare bilateral pan-uveitis in which there is a painful red eye, visual loss and a history of an open globe injury. The risk of sympathetic ophthalmia has been quoted as $0.14 \%$ in a large scale civilian study of penetrating eye injuries in South Africa [10], and in less than 1/500 cases of open globe injury [11]. Colyer et al [8] reported no episodes of sympathetic ophthalmia in 25 enucleations on US servicemen evacuated from Iraq to the Walter Reed hospital between 2003- 2006. Freidlin et al [12] in 2006 published a case report about a 21-year-old US soldier who received a penetrating eye injury while fighting in Iraq and was treated with evisceration. Sympathetic ophthalmia developed, which responded well to steroid treatment. They stated that it was the first case of sympathetic ophthalmia after a war injury reported since World War II. In 
the time period covered in this article neither evisceraton or enucleation resulted in postoperative complications. We would therefore conclude that both techniques appear safe but feel that overall evisceration carries better cosmesis than enucleation.

The management of devastating ocular trauma is addressed in the head and neck component of the Military Operational Surgical Training (MOST) course. This new course, delivered entirely by consultant surgeons is designed to teach all newly deploying surgeons the theoretical and practical concepts behind the surgical techniques currently required on deployment. These techniques may be outside of the routine civilian practice of that surgeon, as is the management of devastating ocular trauma by OMFS surgeons. Both enucleation and evisceration are taught by consultant ophthalmic surgeons based on cadaveric dissection.

The increased use of ballistic eye protection remains the greatest way of reducing preventable penetrating eye injuries but its uptake amongst servicemen remains variable. Cotter and La Piana modelled data from the Vietnam War and proposed that standard US Army $2 \mathrm{~mm}$ thick defence goggle would have been prevented $52 \%$ of eye injuries [13]. Mader et al [4] analysed 207 eye injuries sustained by US servicemen and commented that polycarbonate ballistic eyewear could have prevented many, but not all, of the injuries. Colyer et al [8] found that during 2003 - 2006, of 61 US servicemen evacuated to the US with perforating eye injuries, only $43 \%$ were wearing eye protection. Servicemen complain that eye protection degrades their vision due to misting, there is a restricted field of view from the frames and that the lenses scratch easily [7]. Further work needs to be undertaken to increase compliance in the wearing of eye protection. Enforced use of eye protection in US military convoys in Iraq in 2004 reduced the incidence of eye injuries to $0.5 \%$ from a conflict wide incidence of $6 \%$ [14], making a strong case for the mandatory 
use of military eye protection by all deployed UK servicemen. 


\section{Conclusion}

The management of penetrating eye trauma is normally outside the routine practice of maxillofacial surgeons in the UK. However improved pre- deployment training and the combined experience of a cadre that has undertaken two long- term deployments has resulted in a large number of surgical interventions for devastating ocular trauma without complications on long- term follow up. Although there is little in the literature to suggest enucleation is more effective than evisceration, the former is undertaken more commonly in both military and civilian environments and was reflected in the proportions performed in our deployment. Many ocular wounds are still potentially preventable and greater emphasis must be placed on exploring reasons why deployed UK servicemen do not always wear ballistic eye protection.

\section{Acknowledgements}

The cases discussed were treated by the third author, however, other maxillofacial consultants; Mr A Gibbons, Mr N McKenzie and Mr A Monaghan also treated similar cases and their figures have been included in the statistics. 


\section{References}

[1] Owens BD, Kragh JF, Wenke JC, Macaitis J, Wade CE, Holcomb JB. Combat wounds in Operation Iraqi Freedom and Operation Enduring Freedom. J Trauma 2008; 64: 295299.

[2] Wade AL, Dye JL, Mohrle CR, Galarneau MR. Head, face, and neck injuries during Operation Iraqi Freedom II: results from the US Navy-Marine Corps Combat Trauma Registry. J Trauma 2007; 63: 836- 840.

[3] Wong TY, Seet MB, Ang CL. Eye injuries in twentieth century warfare: a historical perspective. Surv Ophthalmol 1997; 41: 433- 459.

[4] Mader TH, Carroll RD, Slade CS, George RK, Ritchey JP, Neville SP. Ocular war injuries of the Iraqi insurgency, January-September 2004. Ophthalmology 2006; 113: 97104.

[5] Savar A, Andreoli MT, Kloek CE, Andreoli CM. Enucleation for open globe injury. Am J Ophthalmol 2009; 147(4): 595- 600.

[6] Ophthalmic Care of the Combat Casualty. M.D. Allen B. Thach (Editor), Walter Reed Army Medical Center Borden Institute.

[7] Blanch R, Scott R. Ocular Blast Injury. J Royal Army Med Corps 2009; 155 (4): 279-284

[8] Colyer MH, Chun DW, Bower KS, Dick JS, Weichel ED. Perforating globe injuries during operation Iraqi Freedom. Ophthalmology 2008; 115(11): 2087-93.

[9] Viswanathan P, Sagoo MS, Olver JM. UK national survey of enucleation and orbital implant trends. Br J Ophthalmol 2007; 91: 616- 619.

[10] Du Toit N, Motala MI, Richards J, Murray ADN, Maitra S. The risk of sympathetic opthalmia following evisceration for penetrating eye injuries at Grotte Schuur Hospital. Br J Ophthalmol 2008; 92: 61-63.

[11] Albert DM, Diaz-Rohena R. A historical review of sympathetic ophthalmia and its epidemiology. Surv Ophthalmol 1989: 34: 1-14. 
[12] Freidlin J, Pak J, Tessler H, Putterman A, Goldstein D. Sympathetic Ophthalmia After Injury in the Iraq War. Ophthal Plast Recon Surg 2006; 22 (2): 133-134.

[13] Cotter F, La Piana F G. Eye casualty reduction for eye armour. Mil Med 1991; 156: $126-8$.

[14] Gondusky JS, Reiter MC. Protecting military convoys in Iraq: An examination of battle injuries sustained by a mechanised battalion during operation Iraqi Freedom II. Mil Med 2005; 170; 546- 549. 